\title{
LA MEDIACIÓN PENAL Y EL NUEVO MODELO DE JUSTICIA RESTAURATIVA
}

Mª Auxiliadora García Fernández

Doctora en Derecho y abogada

Email: $\underline{\text { mgf526@ual.es }}$

RESUMEN: Este trabajo pretende analizar el papel de la mediación y su relación con la Justicia Restaurativa, que nace con el movimiento político-criminal a favor de la víctima y la recuperación del papel de la misma en el proceso penal, suponiendo el punto de arranque de una nueva concepción de la justicia aplicable, teniendo como principal instrumento de intervención la figura de la mediación.

PALABRAS CLAVE: Justicia restaurativa, mediación, víctima

ABSTRACT: This paper aims to analyze the role of mediation and its relationship with Restorative Justice, which is born with the political-criminal movement in favor of the victim and the recovery of the role of the victim in the criminal process, assuming the starting point of a New conception of applicable justice, having as main intervention instrument the figure of mediation.

KEYWORDS: Restorative justice, mediation, victim

\section{Antecedentes, concepto, principios e inserción en el sistema de Derecho Penal.}

En el ámbito de las sociedades occidentales, debido a un proceso histórico evolutivo, ha sido el Derecho Penal el encargado de construir un sistema de control formal de los conflictos sociales, basando su actuación en torno a dos pilares: la utilización del concepto de responsabilidad como fundamento del sistema y la asunción de los conceptos de retribución o prevención como fines de la pena. 
Así, la actuación del Estado a través del Derecho Penal no ha situado la atención en el conflicto intersubjetivo que se produce entre dos personas (agresor y víctima) y en la necesidad de ofrecer una solución tanto al propio conflicto como a los implicados en él, sino que lo ha residenciado en el conflicto que se produce entre el actuar de una persona (sujeto activo del delito) y las exigencias de conducta contenidas en las normas penales.

En relación con lo manifestado, la discusión sobre los fines y funciones de la pena ha oscilado entre quienes entienden que la misma cumple una estricta función de retribución al autor del mal causado por el delito (Teorías de la retribución) y quienes por el contrario, atribuyen a la pena una función de prevención de futuros hechos delictivos (Teorías de la prevención). Mientras que desde las teorías de la retribución se mira al pasado, al mal causado por el delito y a la necesidad de proceder a su retribución a la persona de su autor, las teorías de la prevención miran hacia el futuro, intentando evitar la comisión futura de nuevos hechos delictivos ${ }^{1}$.

La atribución a la pena de unas funciones exclusivamente retributivas o preventivo-generales terminó por construir un sistema en el que el Estado trata de responder únicamente a la cuestión relativa a qué hacer con el delincuente que ha desobedecido la norma y a cómo estabilizar el mandato normativo defraudado, olvidándose de los intereses y necesidades de la víctima, a quien no se le permite participar activamente en la solución del conflicto en el que es parte ${ }^{2}$.

La Justicia Restaurativa nace con el movimiento político-criminal a favor de la víctima y la recuperación del papel de la misma en el proceso penal, suponiendo el punto de arranque de una nueva concepción de la justicia aplicable en un determinado país, y teniendo como principal instrumento de intervención la figura de la mediación.

La importancia de su nacimiento nos obliga a intentar centrar sus orígenes, que aunque confusos, podrían datar de 1974 en Ontario (Canadá), donde tuvo lugar el primer programa de reconciliación entre víctima y delincuente llamado VOM (Victim Ofender Mediation). Tras varias iniciativas canadienses, se lanzó el primer programa en Estados Unidos, en Indiana, en 1978, extendiéndose por todo Estados Unidos y Europa.

\footnotetext{
${ }^{1}$ FERREIRÓS C-E., SIRVENT A. Y OTROS: "La mediación en el Derecho penal de menores". Dykinson S.L., Madrid, 2011.

${ }^{2}$ Ibidem.
} 
Lejos de pensar que podría tratarse de un sistema joven y de reciente acogida frente al actual sistema de impartir justicia, residenciado en Jueces y Tribunales, una visión retrospectiva de la Historia, a la que nos hemos referido anteriormente, muestra que esto no siempre ha sucedido así, sino que durante mucho tiempo, hasta la Modernidad, ha existido una pluralidad de focos a los que acudir en busca de justicia ${ }^{3}$, pluralidad que determinaba jurisdicciones variadas, que se regían por el principio de subsidiariedad y que determinaban soluciones diferentes según los casos, los lugares, los juzgadores, etc. ${ }^{4}$.

Algún autor como SOLETO MUÑOZ 5 establece la existencia de varios modelos de Justicia Restaurativa en función de cómo interaccione el sistema penal de cada Estado con los instrumentos propios de ésta, de este modo diferencia tres clases de sistemas:

a) Sistemas complementarios a los Tribunales a través de programas conectados con estos, y que suelen corresponder con sistemas penales más tradicionales. El acuerdo de reparación lo que puede provocar son ventajas procesales para el acusado (reducción de la calificación o de la pena, suspensión, sustitución o beneficios penitenciarios).

b) Sistemas alternativos al enjuiciamiento que van a ser considerados como la verdadera forma de resolución de conflictos debido a que los casos son derivados antes de iniciarse o tramitarse el proceso. Ello es visto con cautela por los países con un sistema penal tradicional y fuertemente instaurado, es el caso de España y otros Estados continentales.

c) Iniciativas ajenas al proceso y la ejecución que buscan más el

\footnotetext{
${ }^{3}$ En este sentido, RIOS MARTÍN, J.C.- PASCUAL RODRÍGUEZ, E. Y OTROS: "la antropología cultural nos ha puesto de manifiesto formas extraordinariamente civilizadas y no violentas de resolver gravísimos problemas en tribus mal llamadas primitivas" en "La mediación penal y penitenciaria. Experiencias de diálogo en el sistema penal para la reducción de la violencia y el sufrimiento humano". Ed.Constitución y Leyes. Madrid, 2008.

${ }^{4}$ OTERO PARGA, M., SOLETO MUÑOZ, H.: "Las raices históricas y culturales de la mediación: Mediación y solución de conflictos. Habilidades para una necesidad emergente". Ed. Tecnos. Madrid, 2007.

${ }^{5}$ SOLETO MUÑOZ, H.: "Aportaciones internacionales al desarrollo de la Justicia Restaurativa en España" en ECHANO BASALDUA Y OTROS: "Justicia restaurativa, una justicia para el siglo XXI: potencialidades y retos". Cuadernos penales José María Lidón, no 9. Ed. Deusto Digital. Bilbao, 2013, pags. 83 y ss.
} 
tratamiento y restablecimiento de las emociones que otro tipo de resarcimiento, como pueda ser el caso de conflictos entre padres e hijos (agresores).

Esta misma autora hace una clara clasificación de los diferentes procedimientos de Justicia Restaurativa, haciendo especial referencia al ya mencionado VOM en cuanto forma más utilizada y extendida de mediación entre víctima y ofensor (España y la mayoría de Estados europeos), matizando que en toda mediación que se realice en el ámbito penal, a diferencia del civil, lo importante no es tanto el acuerdo como el diálogo, ya que lo que se pretende es, no sólo dar su lugar a la víctima, responsabilizar al agresor y reparar el daño sino también canalizar emociones y sentimientos.

\section{Continuando con la mencionada clasificación encontramos:}

- $\quad$ la conferencia de grupo familiar o conferencia comunitaria como forma de facilitación que se desarrolla entre el agresor y la víctima junto a personas del entorno familiar, escolar o social donde tratan el daño producido y cómo se puede reparar, quedando al margen del proceso judicial.

los círculos sentenciadores son similares a los anteriores pero con la participación del propio tribunal que es el que deriva los casos y los controla. Incluso puede llegar el juez a participar en dicho círculo, normalmente como simple mero transcriptor del acuerdo adoptado en la sentencia, aunque si no hay consenso puede llegar a participar activamente. Curiosamente este método se utiliza en Estados Unidos en ilícitos realizados por menores, además de en otros delitos cometidos por adultos en vía penal.

los paneles restaurativos se alejan un poco del sistema restaurativo, dado que no incluyen a la víctima en sus reuniones con el agresor, e incluso el papel de éste queda relegado a un segundo plano, su principal propósito es la reparación. De modo que cuando el agresor asume su culpa en el proceso penal, el juez le ofrece acudir a este panel, panel 
formado por ciudadanos, una vez producida la reunión, procede a discutir la reparación con la víctima. Se lleva a cabo un seguimiento para constatar el cumplimiento de las medidas, si éstas no se han cumplido, el asunto vuelve al juez para que establezca la pena en sentencia.

la mediación comunitaria se realiza mediante la creación en barrios y escuelas de centros comunitarios para dar formación en resolución de conflictos. Estos centros realizan mediaciones y facilitaciones en ámbitos escolares y vecinales sin relación con los tribunales, pero también civiles y penales por derivación del órgano judicial.

Se considera que el trabajo publicado en los años setenta por HUDSON \& GALAWAYS' $^{6}$ es una de las mayores aportaciones al concepto de Justicia Restaurativa, término promovido en el Congreso Internacional de Criminología celebrado en Budapest en 1993. La mayoría de la doctrina entiende que el fundamento de este nuevo modelo de Justicia está en la obra de CHRISTIE, y concretamente en su artículo "Conflicts as Property", publicado en 1976, donde manifiesta la necesidad de establecer una alternativa al sistema penal tradicional que permita una solución diferente en relación a los conflictos ${ }^{8}$.

El primer autor que realizó un trabajo de compendio integral y comprensible del modelo de Justicia Restaurativa fue ZEHR, "Retributive Justice, Restorative Justice, New Perspectives on Crime and Justice” (1985), y más tarde en el libro llamado “Changing Lenses" (1990) ${ }^{9}$. Al igual que CHRISTIE, presenta el modelo de Justicia Restaurativa como un paradigma alternativo de Justicia, en oposición al sistema tradicional de Justicia Retributiva. En su visión presenta los beneficios que para las

\footnotetext{
6 HUDSON, J. Y GALAWAY, B.: "Restitution in Criminal Justice: A Critical Assessment of Sanctions". Ed. Lexington Books, 1977.

${ }^{7}$ CHRISTIE, N., "Conflicts as Property", British Journal of Criminology, vol. 17, n 1, trad. al español en MAIER, J.: "De los delitos y de las víctimas", Ad Hoc, Buenos Aires, 1992.

${ }^{8}$ Christie considera que los conflictos no siempre pueden ser resueltos, pues a veces solo podemos pretender vivirlos y manejarlos del mejor modo posible; por lo tanto, el mal a evitar está en el modo en que la racionalidad jurídica disecciona y trata el fenómeno delictivo, incapaz de penetrar en la realidad de los problemas sociales y humanos con una mirada más abierta y profunda. CHRISTIE, N. 2013: «Words on words». International Journal of Restorative Justice, n. ${ }^{\circ} 1$ en TAMARIT SUMALLA, J.M.: "El necesario impulso de la Justicia restaurativa tras la Directiva europea de 2012". Ars Iuris Salmanticensis: revista europea e iberoamericana de pensamiento y análisis de derecho, ciencia política y criminología. Vol. 1, Junio 2013. ISSN: 2340-5155. Pág. 141.

9 ZEHR, H.: "Retributive Justice, Restorative Justice. New Perspectives on Crime and Justice" (Issue \#4). Akron, PA: Mennonite Central Committee Office of Criminal Justice, September, 16p. 1985; y "Changing Lenses: A New Focus for Crime and Justice" (Trocando as Lentes: Um Novo Foco sobre Crime e Justiça). Scottsdale, PA: Herald Press, 271p. 1990.
} 
víctimas y los delincuentes supone la asunción de la responsabilidad de los hechos, haciendo bien lo mal hecho previamente, reparando el daño causado. Afirma que la interacción víctima-victimario supone una reestructuración de los daños morales y materiales $^{10}$.

Cabría preguntarse por las causas que han propiciado el surgimiento y posterior evolución de la Justicia Restaurativa y con ella la figura de la mediación, situando como tales: la recuperación del papel de la víctima, la crisis del modelo resocializador, la aparición de las teorías abolicionistas, el nacimiento del modelo de Resolución Alternativa de conflictos y la crisis del sistema legal y del Estado social.

Tras el pertinente estudio de la corriente restaurativa, parece quedar claro cuáles son sus principios y exigencias a nivel internacional, así TAMARIT SUMALLA manifiesta que los principales son:

a) protagonismo y «empoderamiento» de las personas involucradas en el conflicto; b) voluntariedad; c) centralidad de la víctima; d) reconocimiento del papel de la comunidad; e) apertura a nuevas prácticas restaurativas; f) importancia de la dimensión emocional y comunicativa del proceso; g) no exclusión de delitos con base en criterios apriorísticos, según la idea de que los límites los fijan las partes; h) atención a la evaluación empírica de los programas; i) Complementariedad y autonomía en relación con el sistema de justicia penal.

Mientras que otros aspectos son, sin embargo, más controvertidos:

a) el rol del facilitador, particularmente su profesionalidad; b) la forma de articulación con la justicia penal y los efectos procesales o en la ejecución de la pena; c) el modelo restaurativo, en el que puede primar la idea de encuentro, el resultado reparador o el ideal de transformación; d) el papel que puede desempeñar la idea de reconciliación; e) los efectos reales del proceso sobre sus protagonistas ${ }^{11}$.

\footnotetext{
${ }^{10}$ TRUJILLO, J., "Mediation: World it work in Spain too? Universidad de Lovaina, Bélgica, faculty of Law, Master in European Criminology, 2000. Obra citada por GORDILLO SANTANA, L.F.: "La Justicia Restaurativa y la mediación penal”. Ed. Iustel. Madrid, 2007.

11 TAMARIT SUMALLA, J.M.: "El necesario impulso de la Justicia restaurativa tras la Directiva europea de 2012". Ars Iuris Salmanticensis: revista europea e iberoamericana de pensamiento y análisis de derecho, ciencia política y criminología. Vol. 1, Junio 2013. ISSN: 2340-5155. Págs. 143 y 144.
} 
Fue a partir de la década de los años cincuenta del siglo pasado cuando, gracias a los estudios criminológicos de campo, se comenzó a hacer una llamada de atención sobre este proceso de desposesión del conflicto al que se había sometido a las víctimas y de los perjuicios que conllevaba ${ }^{12}$. Ya entonces se empezó a tomar poco a poco conciencia de que "el conflicto antes que del Estado es de la víctima y del victimario"13, propugnando nuevas soluciones paliativas a dicha situación de marginación, así como abogar activamente a favor de la creación de nuevos espacios de participación de la víctima en los mecanismos de resolución de un conflicto -el delictivo- del que es parte determinante.

Este proceso de redescubrimiento de la víctima implicó el advenimiento de una nueva disciplina en el seno de la Criminología, la Victimología ${ }^{14}$, la cual se dirigía a estudiar su posición en el conflicto y en su solución, los factores que determinan la victimización, así como los marcadores de peligro o los efectos perniciosos que, más allá del propio conflicto, le depara el propio sistema policial y judicial (victimización secundaria), entre otros muchos aspectos ${ }^{15}$.

Una corriente doctrinal que tuvo profundo calado en lo concerniente a la evolución del Derecho Penal fue la representada por la teoría de la resocialización, la cual buscaba como último fin de la pena, la resocialización del delincuente, de modo que si se actuaba sobre la persona que había delinquido para que modificara su conducta adaptándose a los parámetros legales, ésta no reincidiese en un futuro. Ello supondría un auge de las corrientes preventivo-especiales tendentes a lograr la reinserción del

\footnotetext{
12 FERREIRÓS C-E., SIRVENT A. Y OTROS: “La mediación en el Derecho penal de menores”. Ed. Dykinson S.L. Madrid, 2011.

${ }^{13}$ GORDILLO SANTANA, L.F.: “La Justicia Restaurativa y la mediación penal”, op. cit., pág. 356.

${ }^{14}$ En el nacimiento de esta nueva disciplina y, con ello, en el proceso de redescubrimiento de la víctima, jugó un papel de especial protagonismo la publicación en 1948 de la obra de VON HENTIG: "El criminal y su víctima". Hecho que pone de manifiesto MORILLAS FERNÁNDEZ Y OTROS: "Su obra The criminal and his victim en el año 1948, podría calificarse como el punto de partida de estudios científicos sobre la víctima del delito, pues si bien no supuso un cambio de perspectiva radical respecto a la Victimología, sí que se contempló con gran interés su alusión a una clasificación tipológica de las víctimas". MORILLAS FERNÁNDEZ, D.L.; PATRÓ HERNÁNDEZ, R.M. y AGUILAR CÁRCELES, M.M ${ }^{\mathrm{a}}$ en "Victimología: un estudio sobre la víctima y los procesos de victimización”. Ed. Dykinson, S.L. Madrid, 2011. Pág. 157.

${ }^{15}$ En palabras de TAMARIT SUMALLA, J. M".: "La victimización secundaria constituye el conjunto de costes personales que tiene para la víctima de un hecho delictivo su intervención en el proceso penal en el que éste es objeto de enjuiciamiento. El concepto comprende los efectos traumatizantes derivados de los interrogatorios policiales o judiciales, la exploración médico-forense o el contacto con el ofensor en el juicio oral. En un sentido más extenso cabe también considerar efectos el tratamiento informativo del suceso por parte de los medios de comunicación”. TAMARIT SUMALLA, J.M ${ }^{\mathrm{a}}$ Y OTROS: “La Victimología: cuestiones conceptuales y metodológicas”. Manual de Victimología. Ed. Tirant lo Blanch. Valencia, 2006.
} 
delincuente. En este sentido, se analiza por MORILLAS FERNÁNDEZ la incidencia que tiene la victimología en la criminología, de modo que establece una faceta eminentemente preventiva, marginando los métodos represivos, para la adopción de nuevas formas de solución de conflictos -conciliación, mediación- junto al estudio de las principales variables concurrentes en la víctima - personalidad, victimización, etc.-- ${ }^{16}$

Es la propia Constitución Española de 1978 la que reivindica dicha idea resocializadora y la proclama abiertamente en su artículo 25.2: “las penas privativas de libertad y las medidas de seguridad estarán orientadas hacia la reeducación y la reinserción social". Si bien se ha de matizar que, pese a ser uno de los fines de la pena, no es el único fin de la misma ni tampoco el más importante.

Esta idea de resocialización y sus ideales preventivos especiales se resumen en lo que se conoce como tratamiento penitenciario que, junto con figuras como la sustitución de la pena, la remisión condicional de la misma o la libertad condicional, configuran los parámetros legales que la avalan.

Es por todo ello que supondría el momento oportuno para que el modelo de Justicia Restaurativa hiciera su aparición ${ }^{17}$, al basarse en la búsqueda de una solución reparadora al conflicto, donde el propio delincuente además de ser sancionado por sus actos, va a tomar conciencia de los mismos y va a tratar de reparar el daño ocasionado.

Actualmente, y debido a nuevos condicionamientos sociales, se ha producido un resurgir de ideologías neopunitivistas, ello por la profunda crisis que sufren algunas instituciones y que calan de manera negativa en la comunidad provocando sentimientos de inseguridad o incluso venganza. Ello ha terminado por generar, en palabras de algunos autores, una extraña cohabitación entre estos dos polos de evolución del moderno Derecho Penal: una corriente humanizadora del Derecho Penal con base en el

\footnotetext{
${ }^{16}$ MORILLAS FERNÁNDEZ, D.L.; PATRÓ HERNÁNDEZ, R.M. y AGUILAR CÁRCELES, M. M ${ }^{\mathrm{a}}$ en "Victimología: un estudio sobre la víctima y los procesos de victimización". Ed. Dykinson, S.L. Madrid, 2011. Pág. 44.

${ }^{17}$ Algunos autores como CABEZUDO RODRÍGUEZ, aunque partidario de medidas de resolución de conflictos alternativas a las vías más punitivas, estiman que este modelo y sus principios se insertan mejor en el derecho privado, siendo de dudosa acomodación a la esfera pública. MORILLAS FERNÁNDEZ, D.L.; PATRÓ HERNÁNDEZ, R.M. y AGUILAR CÁRCELES, M. $\mathrm{M}^{\mathrm{a}}$ en "Victimología: un estudio sobre la víctima...”. Op. cit. Pág. 342.
} 
modelo de Justicia Restaurativa y una corriente neoretribucionista cuya finalidad sería el endurecimiento del sistema ${ }^{18}$.

No sólo las teorías resocializadoras supusieron un apoyo e impulso de la llamada Justicia Restaurativa sino que además otras corrientes extremadamente críticas con el formalismo exacerbado del modelo actual de Derecho Penal, conocidas usualmente como teorías abolicionistas, contribuyeron a crear un caldo de cultivo idóneo para su instauración y difusión.

Estas teorías abolicionistas vienen a denunciar la apropiación que del conflicto entre delincuente y víctima hace el Estado a través de su brazo ejecutor, el Derecho Penal, abogando por la desaparición total del sistema de Justicia penal concebido como tal en la sociedad actual.

CHRISTIE, en su trabajo "Conflicts as Property", afirma que los juristas, los fiscales, los jueces y los profesionales se han apropiado de los conflictos, incluidos los crímenes, con el resultado del olvido de las personas directamente implicadas en su génesis ${ }^{19}$. Es la marginación a la que se ve sometida la persona que ha sufrido el daño producido por el delito y que obligatoriamente debiera ser consultada sobre el modo en que ha de ser reparado el mismo.

Pese a la coincidencia en ambos postulados, en determinados principios como la necesidad de participación de víctima y autor del delito en la solución del conflicto, los defensores de la Justicia Restaurativa no pretenden la supresión completa del sistema de Justicia penal, como así lo manifiestan los partidarios de las teorías abolicionistas, sino que tratarían de ser una alternativa a ese Derecho Penal de carácter eminentemente formalista.

Autores como CRUZ BLANCA, consiguen estructurar de manera clarificadora los distintos modelos o fases por las que ha pasado el Derecho Penal de menores. Así, desde el modelo tutelar con una visión paternalista y protectora de actuación, pasando por el modelo resocializador o educativo, donde dicha idea prima sobre cualquier otra forma de intervención, hasta el modelo mixto o de responsabilidad actual que

\footnotetext{
${ }^{18}$ FERREIRÓS C-E., SIRVENT A. Y OTROS: “La mediación en el Derecho penal de menores”. Ed. Dykinson S.L., 2011.

${ }^{19}$ CHRISTIE, N., "Conflicts as Property”. British Journal of Criminology, vol. 17, $\mathrm{n}^{\circ}$ 1, trad. al español en MAIER, J.: "De los delitos y de las víctimas", Ad Hoc, Buenos Aires, 1992.
} 
"propugna no sólo la posibilidad de intervenir exclusivamente frente a la comisión de hechos delictivos, sino que además se propone un programa despenalizador que reduzca sustancialmente la intervención penal en el ámbito de los menores (...) mediante la reducción de la imposición de las medidas privativas de libertad a favor de aquellas otras ambulatorias o de carácter abierto"20.

A juicio de MARTÍNEZ ESCAMILLA, hoy por hoy la justicia penal, por supuesto mejorable, no debe dejar de ser conceptuada como un servicio público, sin que este modelo tan crítico, el abolicionista, esté en condiciones de suplir satisfactoriamente las garantías que nos ofrece el actual sistema penal ${ }^{21}$.

Quizás se trate de teorías -las abolicionistas- profundamente dramáticas en sus premisas y fundamentos pero que, a su vez, han conseguido abrir una profunda brecha en las concepciones rígidas y formales en las que se incardina el sistema legal de las sociedades actuales que se asienta sobre la base de un deficiente Derecho Penal que no responde a necesidades y expectativas concretas, no ya de futuro, sino incluso de presente.

Es por todo ello y a raíz de las diferentes manifestaciones de insatisfacción con la Administración de justicia en EEUU y Canadá junto con la preocupación sostenida de parte de la doctrina, por lo que surgen corrientes de deslegalización y desjudicialización de los conflictos dictándose en 1980 la Dispute Resolution Act, donde se regulaban los proyectos iniciales de mediación. El movimiento se denominó genéricamente Alternative Dispute Resolution (ADR) y actualmente está experimentando un "reciclaje" en cuanto a la búsqueda de nuevas fórmulas de regulación de conflictos. ${ }^{22}$

Históricamente, se ha pasado de sociedades que dirimían sus conflictos internamente a sociedades que ceden poder al Estado, para que en nombre de la comunidad instaure las normas necesarias para la resolución de conflictos. La constante evolución social ha generado, dada la lenta adaptación de los sistemas de justicia a ésta,

\footnotetext{
${ }^{20}$ CRUZ BLANCA, Ma . J.: "Derecho penal de menores". Ed. Instituto de Criminología de Madrid. Editoriales de Derecho Reunidas S.A. Madrid, 2002. Pág. 102. Esta autora hace esta afirmación con cita de GARCÍA PÉREZ, O.: "Los actuales principios del Derecho penal juvenil: un análisis crítico". Revista de Derecho penal y Criminología, no 3. Enero de 1999. Pág. 39.

${ }^{21}$ MARTÍNEZ ESCAMILLA, M., Y SÁNCHEZ ÁLVAREZ, Ma. P.: “Justicia Restaurativa, Mediación penal y penitenciaria: un renovado impulso”. Editorial Reus, SA. Madrid, 2012.

${ }^{22}$ Ya en Europa incluso se fomenta que, en determinados casos, la mediación sea obligatoria. Vid. HERRERA DE LAS HERAS, R.: "La Mediación Obligatoria para Determinados Asuntos Civiles y Mercantiles", en InDret, Vol. 1, 2017.
} 
un movimiento que busca obtener soluciones rápidas y eficaces con participación ciudadana, provocando una crisis del Estado de Bienestar y consecuentemente del sistema penal en él empleado. Sería el modelo de Justicia Restaurativa una clara respuesta a estas necesidades ${ }^{23}$.

La evidente crisis de legitimación que sufre hoy el Derecho Penal "convencional" ha propiciado, en no escasa medida, la difusión de nuevos modelos de intervención social menos formalizados y, pretendidamente, más eficaces ${ }^{24}$. El auge de la mediación o conciliación víctima-ofensor para hacer posible un acuerdo de contenido reparador es buena prueba de ello ${ }^{25}$.

Es por esto que la aparición de la Justicia Restaurativa ha supuesto una profunda crisis en el modelo de justicia retributiva, dado que sus características ponen en tela de juicio las bases de esta última, características entre las que se encuentran la informalidad del procedimiento a seguir, manifestándose éste como una vía flexible y ágil, junto a la voluntariedad y responsabilidad de las partes en el mismo. Es también a través del instrumento de la mediación que se logra el cumplimiento eficaz de los acuerdos alcanzados y la disminución de los casos de reincidencia.

En el sistema judicial en general existe un alto índice de reincidencia, ejecuciones de sentencia o modificaciones de medidas, generando ineficacia y lentitud en los Juzgados, cosa que intenta prevenir la Justicia Restaurativa evitando la revictimización.

\footnotetext{
${ }^{23}$ MARTÍNEZ DE PISÓN, J.M.: "Derechos humanos y problemas de fundamentación". Ed Tecnos, 1999.

${ }^{24}$ En este sentido se manifiesta LORENZO MORILLAS CUEVA cuando analiza la necesidad de reformas y cambios en nuestro Derecho Penal: "Es conveniente precisar como epílogo a todo lo escrito que las medidas, los cambios, las reformas, tanto en la esfera del Derecho Penal sustantivo como procedimental, no han de presentarse como la culminación de un proceso que terminará por solucionar el conflicto. Las prioridades tienen que dirigirse hacia políticas sociales previas y acciones preventivas, asistenciales, de intervención social, educativas, coherentes con los objetivos a conseguir; todo ello asentado en adecuadas inversiones que atenúen en lo posible los efectos de semejantes conductas y potencien las anteriores exigencias básicas. En esta línea es fundamental entender que el Derecho Penal tiene que mantener su sometimiento a los principios fundamentales que lo orientan en el Estado social y democrático de Derecho, y más especialmente su vocación y exigencia de ultima ratio entre los demás sectores del Ordenamiento jurídico; reservado, en definitiva, para los supuestos de mayor gravedad, incluso en estas deleznables conductas que analizamos.

Dicho lo anterior, es necesario igualmente señalar que la intervención punitiva se hace, en estas circunstancias, inevitable. Cierto es que a nuestro Código Penal después de las reformas que en esta materia se han producido hay que valorarlo positivamente, sin que ello suponga que no sea necesario seguir mejorando sus contenidos". Encuentros "violencia doméstica". "El Derecho Penal y la violencia doméstica”. Ed. CGPJ. Centro de documentación jurídica. Madrid, 2004. Págs. 276 y 277.

${ }^{25}$ ALASTUEY DOBÓN, M. C.: "La reparación a la víctima en el marco de las sanciones penales". Ed. Tirant lo Blanch. Valencia, 2000, pág. 234.
} 
En este sentido, y como manifestamos anteriormente, se debe proceder a la inserción del instrumento de la mediación en el sistema legal, dentro del ámbito judicial, pero como una herramienta más, sin prescindir de ningún contenido o método y creciendo paralelo al sistema ya institucionalizado.

Así, se contempla y se introduce en el Derecho penal de menores, la reparación y conciliación en los artículos 19 y 51 de la LO 5/2000, de 11 de enero, Reguladora de la Responsabilidad Penal del Menor (en adelante LORPM) a diferencia de la legislación penal de adultos que no contempla esta figura, y que tan sólo podríamos otorgarle eficacia a través de determinados instrumentos, como pueda ser el perdón del ofendido, cuando esté previsto por la ley como ocurre en las faltas perseguibles a instancia de parte (art. $639 \mathrm{CP}$ ), en los delitos de calumnias e injurias (art. 215.3 CP), en daños causados por imprudencia grave $(267.3 \mathrm{CP})$ y pocos casos más. También puede ocurrir que en un proceso por delito, si se llega a un acuerdo durante la fase de instrucción, el Ministerio Fiscal puede tenerlo en cuenta a la hora de elaborar su escrito de acusación y solicitar pena, pudiéndose llegar a una conformidad en función de la acción mediadora y acuerdo alcanzado (art. 738.4 LECr.) e incluso tras el auto de apertura de juicio oral (art. 787 LECr).

Es posible encontrar consecuencias penológicas al utilizarse la mediación y conseguir un posible acuerdo mediante la circunstancia de reparación del daño (art. 21.5 $\mathrm{CP}$ ), aplicable como atenuante simple o muy cualificada. En fase de ejecución, la mediación puede ser valorada de cara a la suspensión (arts. 80 y ss CP) o sustitución de la pena (art. $88 \mathrm{CP}$ ), pudiéndose imponer el cumplimiento del acuerdo al que se hubiera llegado como condición a satisfacer durante el período de suspensión. Además puede ser tenida en cuenta a la hora de emitir informes favorables al indulto y adoptar la suspensión a la que hace referencia el art. 4.4 CP.

En fase de ejecución penitenciaria pueden ser tomados en consideración la mediación y el acuerdo de reparación en la aplicación de figuras que suponen una cierta ampliación de los márgenes de libertad, tales como la clasificación en régimen abierto (art. 72.5 y 6 LOGP y art. 80 y ss. RP), la concesión de permisos penitenciarios (art. 47 LOGP), la exclusión del período de seguridad del art. $36.2 \mathrm{CP}$, así como para la concesión de la libertad condicional ordinaria o anticipada (arts 90 y ss CP). 
Tan hondo calado están teniendo estas teorías restaurativas que en nuestro país ya existe un Anteproyecto de Ley Orgánica del Estatuto de la víctima del delito, de 24 de octubre de 2013, convertido en Proyecto de Ley en fecha 5 de septiembre de 2014, que alude a la justicia reparadora como derecho que asiste a la víctima y como procedimiento idóneo para una adecuada reparación material y moral de los perjuicios derivados del delito ${ }^{26}$.

Todo ello provoca inevitablemente que se cuestione la posible colisión entre el principio de legalidad y el principio de oportunidad, dando la impresión de tratarse de dos vías distintas de solución de un conflicto. Aportaciones de autores como ROXIN ponen de manifiesto la existencia de un punto de unión y la complementariedad de ambos modelos, esto es, el proceso de mediación no elude la intervención del sistema penal, ni anula el papel de la administración de justicia. En este sentido, la mediación no supone una privatización de la justicia penal, porque corresponde al Estado, de un lado definir y delimitar el marco de la mediación -sus límites objetivos, subjetivos, formales y estructurales- y de otro garantizar el cumplimiento de las garantías procesales, evitando eventuales abusos que pudiesen ocurrir. Se trata más bien de incluir de una manera más activa a la víctima y al infractor en el proceso, con el objetivo de la reparación, la responsabilización del daño y la petición de perdón -disculpas-, sin que se realice únicamente en el ámbito privado, sino también en el público, con la trascendencia social que permiten las salas de administración de justicia. La mediación, por tanto no viene a suplir al sistema de justicia penal existente, sino a complementarlo, humanizarlo y racionalizarlo. En último extremo sirve para acallar los sentimientos de venganza de las víctimas en la petición de un incremento punitivo del Estado que nada aporta a la pacificación y a la convivencia $\operatorname{social}^{27}$.

Es cierto que existen voces que discrepan de lo hasta ahora manifestado o que por los menos son cautos a la hora de definir o incluso situar el lugar que ha de ocupar

\footnotetext{
${ }^{26}$ Vid. Anteproyecto que dimana de la Directiva 2012/29/UE del Parlamento Europeo y del Consejo, de 25 de octubre de 2012, por la que se establecen normas mínimas sobre los derechos, el apoyo y la protección de las víctimas de delitos, y por la que se sustituye la Decisión marco 2001/220/JAI del Consejo, y que en sus artículos 3, 5.1.k), 15 y 29 hace expresa alusión a servicios de justicia restaurativa. Vid. Proyecto de Ley del Estatuto de la víctima del delito de 5 de septiembre de 2014. Boletín Oficial de las Cortes Generales no $115-1$.

${ }^{27}$ RIOS MARTÍN, J.C.- PASCUAL RODRÍGUEZ, E. Y OTROS: “La mediación penal y penitenciaria. Experiencias de diálogo en el sistema penal para la reducción de la violencia y el sufrimiento humano". Ed. Colex, $2^{\mathrm{a}}$ ed. Madrid, 2008.
} 
la Justicia Restaurativa y concretamente la mediación en nuestro sistema legal. Así, autores como MARTÍN DIZ afirman que "conjuntar un sistema de mediación penal con un proceso jurisdiccional como el actualmente vigente en España supone afectar, de una u otra forma, la médula espinal de la justicia penal, y muy especialmente en lo relativo a la disponibilidad de la acción penal y de los derechos materiales subyacentes. Sobre todo en la línea de aplicación del binomio oportunidad-dispositivo y del principio de necesidad-legalidad ${ }^{, 28}$.

Es por todo ello que creemos que se trataría de un principio de oportunidad que buscase no sólo la celeridad y el aligeramiento de la justicia sino también una justicia más práctica y eficaz dentro del propio sistema reglado, hecho que entroncaría directamente con el principio de intervención mínima que informa el Derecho Penal y que cuenta como fundamento axiológico el evitar la penalización excesiva de un conflicto, acudiendo sin más al ius puniendi del Estado como instrumento para salvaguardar la paz social.

Existen ciertos problemas a la hora de dar una definición común de Justicia Restaurativa, aunque se pueden encontrar determinados mínimos que la conforman, coincidiendo diversos autores en la existencia de un proceso de diálogo entre las partes para la solución de un conflicto en el que se hayan inmersas y que es sumamente beneficioso tanto para víctima como para victimario, protegiendo la paz social y otorgándoles la disponibilidad sobre dicho proceso, procurando la responsabilización del infractor y la reparación del daño a la víctima y a la comunidad con la consecución de un posible acuerdo.

Los principios que definen la Justicia Restaurativa son los siguientes ${ }^{29}$ :

1.- La reparación nace del movimiento a favor de la víctima y la recuperación de su papel en el proceso penal.

\footnotetext{
${ }^{28}$ MARTÍN DIZ, F.: “La mediación: sistema complementario de Administración de Justicia”. CGPJ. Madrid, 2010, p. 306.

${ }^{29}$ GIMÉNEZ- SALINAS I COLOMER, E.: "La mediación: una visión desde el derecho comparado", en ROSSNER, D., Y OTROS: "La mediación penal". Centro de Estudios Jurídicos y Formación Especializada de la Generalitat de Cataluña”. Barcelona, 1999, pp. 94 y ss.
} 
2.- La reparación cumple no solamente una función individual del autor respecto de la víctima, sino también un fenómeno pacificador propio del Derecho penal.

3.- La reparación penal no se puede confundir con la indemnización civil a las víctimas.

4.- La voluntariedad en la reparación es un punto crucial.

5.- La reparación forma parte de un concepto de justicia negociada aunque no por ello más rápida.

\section{6.- La Justicia reparadora se sitúa en el seno del Derecho penal.}

En definitiva, y dadas las especiales características que configuran la Justicia Restaurativa, hemos de abogar por su integración y evolución dentro del sistema penal como un complemento o, incluso, como una alternativa a éste, considerando que los instrumentos restaurativos procederán únicamente cuando se den determinadas circunstancias, esto es, cuando exista un indicio fuerte de culpabilidad, delito flagrante o reconocimiento de hechos, no reincidencia o escasa y voluntad de reparar, entre otros, pero siempre valorándose cada caso concreto. Ejemplo de estas nuevas corrientes es la apuesta que por la mediación hacen las Instituciones internacionales, entre ellas la Unión Europea y Naciones Unidas.

\section{Mediación como garantía de tutela judicial efectiva.}

Analizar el significado de garantizar, dar garantía de que una cosa va a suceder o realizarse, implica prever que la figura de la mediación no supone un impedimento para que cualquier ciudadano pueda obtener la tutela de jueces y tribunales, es más, supondría ampliar el contenido de dicho derecho, teniendo como telón de fondo el principio de seguridad jurídica, el cual se podría definir como la última ratio de todos los derechos reconocidos por el ordenamiento.

Revisando nuestros propios antecedentes, este derecho a la tutela judicial efectiva, no ha sido siempre tan concluyente, de modo que nuestra Constitución de 1812, por puras razones históricas, no reconocía este derecho como tal e incluso parecía 
limitar la intervención de los jueces potenciando otras formas de solución de conflictos (arts. 280 y ss. de este texto constitucional).

Hemos de partir de que ya el precedente, digámoslo así, de la mediación, que podría ser el arbitraje, es un procedimiento que, de forma alternativa, pretende resolver con garantías una controversia jurídica. Pero aunque el arbitraje es producto del ejercicio de la libertad de los ciudadanos frente al Estado, es el mismo Estado quien "asegura a los ciudadanos el derecho a la tutela judicial efectiva, no como un derecho de libertad, pero sí como un derecho prestacional, aunque no puede imponer a los ciudadanos el ejercitar ese derecho, tampoco puede limitar la libertad de esos ciudadanos para acudir a otros sistemas de decisión de sus controversias" ${ }^{" 30}$.

El artículo 24 de la CE, garantiza el derecho fundamental a la tutela judicial efectiva $^{31}$. Este es un derecho básico que se protege a través de diversas leyes, dentro de las cuales está la ley de Arbitraje (art. 24.1 LA). Evidentemente, nos hemos de referir en concreto al procedimiento arbitral puesto que se encuentra legalmente regulado y existe incluso Jurisprudencia al respecto, compartiendo como comparte los fundamentos básicos de la mediación aunque se diferencien en determinadas formas.

Quienes optan por la vía arbitral no están renunciando a la tutela judicial efectiva de los tribunales del Estado en el ejercicio de sus derechos e intereses legítimos sino que se están poniendo de acuerdo para utilizar una vía alternativa al proceso legal. Esto es reflejo de la libertad, valor superior del ordenamiento jurídico, junto con la justicia y la igualdad (art. 1.1 CE). La Constitución española no impone acudir a la jurisdicción de

\footnotetext{
${ }^{30}$ MONTERO AROCA, J.: "Artículo 2. Materias objeto de Arbitraje", en Comentarios a la Ley de Arbitraje (Ley 60/2003, de 23 de Diciembre), pág. 107. Ed. Civitas S.A., Barcelona, 2004.

${ }^{31}$ Debe escogerse la vía del arbitraje de forma totalmente voluntaria y no debe ser impuesta a las partes, como los arbitrajes forzosos que existieron pero que la Jurisprudencia del Tribunal Constitucional se ha encargado en enmendar, declarando la consiguiente nulidad de dichos preceptos. Tal es el caso del artículo 38.2, párrafo primero, de la Ley 16/1987, de 30 de julio, de Ordenación de los Transportes Terrestres. La Sentencia del Tribunal Constitucional, Sala Pleno, $\mathrm{n}^{\mathbf{0}}$ 174/1995, de 23 de noviembre (Fundamentos de Derecho Tercero y Cuarto), declaró inconstitucional este artículo, ya que establecía un sistema de arbitraje imperativo e institucional, al ser necesario para acceder a la jurisdicción el consentimiento expreso, formalizado en un pacto, de todas y cada una de las partes implicadas en una controversia. Establece la sentencia que "el fin del arbitraje es ser un medio idóneo para descargar a los órganos judiciales del trabajo que sobre ellos pesa y obtener una mayor agilidad en la solución de controversias, pero al hacerlo de forma que no pueda eludirse más que a través de un convenio entre todos los interesados, establece un impedimento para el acceso a la tutela judicial contrario al Derecho de todas las personas a obtener la tutela efectiva de los Jueces y Tribunales en el ejercicio de sus derechos e intereses legítimos".
} 
forma exclusiva y excluyente, sino que admite la solución extrajudicial de los conflictos que se fundamenten en la propia voluntad de los interesados.

Los derechos subjetivos consagrados en el artículo 24 de la CE tienen naturaleza procesal y garantizan ciertas reglas y principios básicos. El ámbito de este derecho a la tutela judicial efectiva es universal, es decir, comprende todo tipo de intereses y derechos legítimos, garantizando que toda situación jurídica tenga una tutela jurisdiccional $^{32}$. Esto no excluye que la resolución de un conflicto se lleve a cabo mediante árbitros, ya que ésta es otra posibilidad legalmente contemplada y por tanto, permitida. A través del arbitraje se ejerce también el derecho fundamental a la tutela de los tribunales, el árbitro debe prestar dicha tutela igual que un juez, aplicando unas mismas garantías constitucionales.

Es clarificadora la propia Exposición de Motivos de la anterior Ley de Arbitraje (1988) cuando establece que: "el convenio arbitral no implica renuncia de las partes a su derecho fundamental de tutela judicial, consagrado en el artículo 24 de la CE”.

Sin lugar a dudas, estipulado legalmente ese derecho de opción y no renuncia, hemos de hacer referencia al principio de autonomía de la voluntad, valor supremo del ordenamiento jurídico, de modo que los ciudadanos puedan optar, como se ha manifestado, por distintos instrumentos para resolver sus controversias, eligiendo lícitamente la vía arbitral cuando ésta ofrezca garantías análogas al proceso jurisdiccional $^{33}$.

Sin embargo, es obligado analizar ese principio de autonomía de la voluntad como punto contradictorio a salvar dentro del marco de la mediación penal en concreto, dado que como tal se inserta dentro de la libertad contractual, característica del Derecho privado y no del Derecho público (derecho penal) en el que rige la norma. Ello reclama una redefinición del papel que tienen establecido los titulares del ius puniendi sin que esto suponga una pérdida de seguridad jurídica, merma de tutela judicial efectiva o en última instancia, incluso pudiera parecer un intento de privatización solapado. Nada más

\footnotetext{
${ }^{32}$ MERINO MERCHÁN, J.: “El equivalente jurisdiccional en el derecho público español”. Centro de Estudios Políticos y Constitucionales, Tribunal Constitucional. Madrid, 2002, pág. 16.

${ }^{33}$ MERINO MERCHÁN, J.: “Tratado de Arbitraje Interno e Internacional”. $2^{\mathrm{a}}$ ed. Civitas SA. Madrid, 1991, pág. 34.
} 
lejos de la realidad dado que es el propio Estado el que va definir y delimitar su marco de actuación, estableciendo sus límites tanto objetivos como subjetivos o formales, ostentando el control posterior a través de los correspondientes órganos (Ministerio Fiscal y Juez).

En una línea similar, el Tribunal Constitucional ha definido reiteradamente al arbitraje como un "equivalente jurisdiccional", garantizando la tutela de los derechos de los ciudadanos por el Estado, afirmando su constitucionalidad y otorgándole al laudo el mismo valor y eficacia que a una sentencia, aunque sea un procedimiento desarrollado de forma privada ${ }^{34}$. "La fuerza jurídica que el ordenamiento jurídico ha venido otorgando y otorga a la decisión arbitral, las garantías de los principios esenciales del proceso que se predican y exigen del sistema arbitral en su conjunto, abogan por la consideración del arbitraje como uno de los medios de tutela que los ordenamientos jurídicos han querido presentar a los ciudadanos. Ese medio de tutela, al que se acude por ejercicio de la libertad, es controlado por el Estado, tanto desde el punto de vista legislativo, es el poder Legislativo el que aprueba la Ley de Arbitraje, como desde el punto de vista del Poder Judicial, a través del ejercicio de la posible anulación del laudo firme (...), o a través de la función de ejecutar lo juzgado por los árbitros

La Sentencia número 176/1996, de 11 de noviembre de 1996, Sala Segunda del Tribunal Constitucional, afirma en su fundamento jurídico cuarto, tras el recurso de amparo presentado alegando menoscabo al derecho de tutela judicial efectiva garantizado en la Constitución por no haber entrado el órgano jurisdiccional a valorar el fondo del asunto, ante una acción de anulación del laudo, que "tal planteamiento, sin embargo, no puede ser compartido, ya que supondría tanto como privar al arbitraje, cuya licitud constitucional hemos declarado reiteradamente (SSTC 43/1988, 233/1988, 15/1989, 288/1993 y 174/1995), de su función como medio heterónomo de arreglo de controversias que se fundamenta en la autonomía de la voluntad de los sujetos privados; lo que constitucionalmente le vincula con la libertad como valor superior del ordenamiento (art. 1.1 CE). De manera que no cabe entender que, por el hecho de

\footnotetext{
${ }^{34}$ Vid. STC 62/1991, de 22 de marzo (Fundamento jurídico $5^{\circ}$ ).

${ }^{35}$ BARONA VILAR, S.: “Arbitraje en España: a la búsqueda de un lugar adecuado en el marco de la justicia. Arbitraje y Justicia en el siglo XXI”. Ed. Thomson Cívitas, Estudios sobre Arbitraje. Pamplona, 2007, pág. 57.
} 
someter voluntariamente determinada cuestión litigiosa al arbitraje de un tercero, quede menoscabado y padezca el derecho a la tutela judicial efectiva que la Constitución reconoce a todos. Pues como ha declarado reiteradamente este Tribunal, el derecho a la tutela judicial efectiva no es un derecho de libertad, ejercitable sin más $y$ directamente a partir de la Constitución, sino un derecho prestacional, sólo ejercitable por los cauces procesales existentes y con sujeción a su concreta ordenación legal (SSTC 99/1985, 50/1990 y 149/1995, entre otras)”.

Es curioso que incluso se argumente para excluir el arbitraje como modo eficaz de tutela judicial, en el caso específico de materia societaria, la existencia de conflictos de competencia con la jurisdicción ordinaria, en virtud del artículo 22 de la Ley Orgánica del Poder Judicial (en adelante LOPJ) y la no existencia de norma expresa en la legislación societaria que lo permita.

Sin embargo, la pretendida competencia judicial exclusiva no puede oponerse como argumento antiarbitral, ya que como la doctrina ha recalcado, una cosa son la reglas de competencia objetiva entre los tribunales del Estado, que las partes no pueden disponer y otra, muy diferente, la libertad de las partes de introducir un pacto arbitral estatutario para resolver sus conflictos.

De todas formas, no resulta apropiado citar el artículo 22.1 de la LOPJ en este contexto, debido a que este artículo regula la extensión y los límites de la jurisdicción española con respecto a la extranjera, determinando qué materias corresponden de forma exclusiva a nuestra jurisdicción; sin que en ningún caso se refiera a la relación entre la competencia de los tribunales con respecto a la arbitral, la cual ha sido expresamente admitida por la Ley de Arbitraje ${ }^{36}$.

No sería correcto pensar que cada ley deba establecer expresamente si admite o no el arbitraje. El artículo 19.1 de la LEC, permite a los litigantes someter a arbitraje el objeto de un juicio e incluso transigir sobre lo que sea objeto del mismo, exceptuando únicamente las materias que la Ley así lo prohíba o establezca limitaciones por razones de interés general o en beneficio de terceros.

\footnotetext{
${ }^{36}$ CAMPO VILLEGAS, E.: "El arbitraje en las sociedades mercantiles", en Revista Jurídica de Catalunya, no 2/1998. Barcelona, pág. 341.
} 
Para evitar confusiones, el poder de transigir se regula de forma autónoma en los artículos 1809 y ss. del Código Civil, concretamente este artículo dice así: " $L a$ transacción es un contrato por el cual las partes, dando, prometiendo o reteniendo cada una alguna cosa, evitan la provocación de un pleito o ponen término al que había comenzado".

De este precepto se desprende que el elemento esencial de una transacción es que ambas partes renuncian a algo en aras de la paz jurídica. Sin embargo, en el arbitraje no es necesario hacer ningún tipo de renuncia, ya que únicamente se presenta como una opción para las partes con el fin de que encaucen el procedimiento a través de un medio diferente a la jurisdicción, pudiendo concederse íntegramente las pretensiones de una sola de las partes, tal y como ocurre en un proceso judicial ${ }^{37}$.

El arbitraje y la transacción tienen en común su fin: la resolución de una controversia sin la intervención de un juez. Pero se diferencian en que la transacción comporta la eliminación instantánea de la litis por obra de las partes, haciéndose concesiones recíprocas, sin que exista una decisión de carácter jurisdiccional motivada, ni un vencedor ni un vencido. En cambio, en el arbitraje el problema es resuelto por un tercero imparcial a través de un procedimiento específico. "Quien compromete no abdica o renuncia a un interés, un derecho o potestad, quien compromete dispone únicamente del derecho jurisdiccional, es decir: el derecho a que la tutela judicial de sus derechos sea administrada por la jurisdicción ordinaria. No por ello renuncia, abdica o transige el derecho sustantivo o su acción. Si se quiere en los términos gráficos del CC -art. 6.2- el compromiso es exclusión voluntaria del orden procesal, pero no de la Ley material aplicable para solventar la controversia o de los derechos en ella reconocidos, 38 .

Visto así, la mediación no puede en ningún caso cercenar el derecho a la tutela judicial efectiva, privando al ciudadano del acceso al proceso judicial, sino todo lo contrario, más bien evita la lesión de ese principio fundamental dado la saturación judicial existente y la dilación de los procedimientos en esa vía. El carácter

\footnotetext{
${ }^{37}$ REGLERO CAMPOS, L.: “El Arbitraje (El convenio arbitral y las causas de nulidad del laudo en la Ley de 5 de Diciembre de 1988)”. Editorial Montecorvo, S.A., Madrid,1991, pág.139.

38 LEIBLE, S., LEHMANN, M.: "El arbitraje en Alemania”, en Arbitraje y Justicia en el siglo XXI, dir. S. Barona Vilar, Thomson Cívitas, Estudios sobre Arbitraje, Pamplona, 2007, pág 158.
} 
complementario de las ADR queda claro y manifiesto en el Libro Verde de la Comisión Europea, donde se aprecia claramente que su uso queda dentro de la tutela que garantiza cualquier Estado a sus ciudadanos, sin renuncia a que ésta pueda ser también de carácter judicial $^{39}$.

En definitiva, en ese derecho a la tutela judicial efectiva de todos los ciudadanos no sólo se desarrollan los derechos del imputado por un hecho criminal sino que también se incluye el derecho de la víctima a obtener información y a participar en el proceso, así lo establece la propia Jurisprudencia en STC de 22 de marzo de $1993^{40}$.

Volviendo a lo manifestado anteriormente, es la seguridad jurídica lo que se intenta preservar a través de nuevos instrumentos de apoyo a la resolución de conflictos, respetando todos y cada uno de los principios jurídico-políticos que conforman nuestra cultura jurídico-constitucional.

El análisis se hace partiendo de la premisa de que la mediación es un instituto que responde a circunstancias históricas que se consolidan en la actualidad (culturales, económicas, sociales...) y a la influencia de la globalización de ideas y de las formas alternativas de resolución de controversias, donde el valor tutelado es la ya mencionada seguridad jurídica, a través de un medio mucho más rápido que el proceso judicial. Por tanto, su carácter voluntario es lo que garantiza la posibilidad de acudir a la tutela de jueces y tribunales, de modo que contribuye a que las resoluciones de éstos sean más eficaces y rápidas, mejorando así todo el sistema judicial.

A pesar del instaurado sistema de libertades y derechos adquiridos por los ciudadanos, es el propio sistema de Justicia el que genera cierta inseguridad e inquietud, siendo el mismo Gobierno español el que ponga en marcha el Pacto de Estado para la Reforma de la Justicia en el año 2001, el cual, en palabras del Ministro de Justicia, "tiene el norte puesto en las necesidades de los ciudadanos", y contempla la agilización y rapidez de la Justicia, la necesidad de potenciar la desjudicialización de

\footnotetext{
${ }^{39}$ Vid. Libro Verde de la Comisión Europea de 19 de abril de 2002, pág. 9: "Las ADR desempeñan un papel complementario con relación a los procedimientos jurisdiccionales, en la medida en que, a menudo, los métodos aplicados en las ADR se adaptan mejor al carácter de los litigios. De esta manera las ADR pueden permitir a las partes entablar un diálogo, que de otro modo hubiera sido imposible entablar, y evaluar por sí mismas la conveniencia de dirigirse a los tribunales".

${ }^{40}$ Vid. Sentencia del TC de 22 de marzo de 1993, nº 98/1993.
} 
conflictos desarrollando e impulsando "fórmulas eficaces de arbitraje, mediación y conciliación" que inciden en el fomento de soluciones pacíficas basadas en el diálogo. En la misma línea, en el Libro Blanco ${ }^{41}$ sobre la justicia, dentro de sus 117 propuestas para el Pacto de Estado, por parte del Consejo General se destacaba la necesidad de acudir a soluciones alternativas y especialmente a la mediación. Por ello, en las citadas propuestas se insistía en incorporar el principio de oportunidad a la legislación penal en base a las experiencias en el campo de justicia de menores ${ }^{42}$.

De todo lo señalado se entiende que la tutela de los derechos fundamentales reconocidos y garantizados por la Norma Constitucional no corresponde exclusivamente al Poder Judicial, sino a todos los poderes del Estado o a cualquier Administración Pública e incluso a todas aquellas instituciones de carácter privado que deben respetarlos y en última instancia hacerlos efectivos (arbitraje, mediación, conciliación, entre otras). De este modo, la tutela judicial efectiva, como acceso a la vía judicial, habría de ser la ultima ratio, el último recurso a utilizar si fallasen otros mecanismos anteriores. Es más, claro ejemplo de que nos hallamos ante modos de tutela judicial efectiva en el caso del uso de mediación, es la existencia de una mediación intrajudicial, derivación a mediación desde dentro del propio proceso. Por la que se ha de concluir que la mediación no se ha de contemplar como una alternativa a la tutela judicial efectiva, sino como una forma más de prestar esa tutela judicial efectiva.

Por último, hacer mención especial, por la trascendencia que pudiera tener en la actualidad, al hecho de que según algún autor, como MEJÍAS GÓMEZ ${ }^{43}$, con el que compartimos opinión, la tutela judicial no sólo se circunscribe a la posibilidad de acudir a los tribunales sino que va más allá, en el sentido de que esa tutela debe abarcar aspectos tales como la empatía, escucha activa, el uso del "lenguaje no verbal", diferenciación entre posición e interés que ha de ejercitar el propio poder judicial y que escasamente ejercita en la práctica, mientras que a través de instituciones como la mediación se fomenta y se aplica continuamente. No sólo se ha de ser eficaz, sino que

\footnotetext{
${ }^{41}$ CASANOVAS POMPEU, MAGRE JAUME Y LAUROBA Ma ELENA (Directores): "Libro Blanco de la Mediación en Cataluña". Edita: Departament de Justícia, Generalitat de Catalunya. Producción editorial: Huygens Editorial, $1^{a}$ Edición, 2011.

${ }^{42}$ GIMÉNEZ-SALINAS, E.: "La Mediación penal en España: el ejemplo de Cataluña". Revista Justicia $i$ Societat, $\mathrm{n}^{\circ}$ 19, Barcelona, 1999.

${ }^{43}$ MEJÍAS GÓMEZ, J. F.: "La mediación como forma de tutela judicial efectiva". Ed. El Derecho y Quantor, SL., Madrid, 2009. Pág. 68 y ss.
} 
ha de humanizarse esa eficacia para conseguir objetivos viables y con posibilidad de futuro.

Es posible pensar que la figura de la mediación ha podido generar tensiones por sus propias características en relación con el principio de presunción de inocencia, que no es más que una manifestación del derecho a la tutela judicial efectiva. Para abordar esta cuestión hemos de comenzar preguntándonos si el hecho de participar en un proceso de mediación puede interpretarse como un reconocimiento de los hechos imputados por parte del presunto autor. Inmediatamente se ha de responder de forma afirmativa si atendemos a que en la mayoría de los casos la satisfacción de las necesidades de la víctima pasa porque el autor reconozca los hechos. Sin embargo, exigir al presunto autor que reconozca los hechos imputados significaría pedirle que admita su autoría y ello, podría suponerle una posterior sentencia condenatoria, tal y como sucede en la figura de la conformidad.

Centrándonos en la cuestión previa, sería oportuno dilucidar si el reconocimiento de los hechos sería necesario para derivar un caso a mediación. Hay autores que niegan tajantemente que la colaboración en el proceso de mediación implique la asunción de autoría, "por lo que no debe requerirse el reconocimiento de hechos, ni como presupuesto para derivar el caso a la mediación, ni como contenido del posible acuerdo" ${ }^{, 4}$.

Creemos que de ningún modo debe la mediación evolucionar de forma paralela a la figura de la conformidad, donde la confesión de los hechos no significa la asunción de responsabilidad ni siquiera que el acusado se considere culpable. A veces, todo ello supone la renuncia de quien se considera inocente a apostar por un juicio en el que no las tiene todas consigo y de donde puede salir "peor parado"45.

Por ello, y porque en muchos casos en la información que se proporciona al imputado sobre la mediación se contiene expresamente que su fin es la reparación del daño causado, no es de extrañar que su aceptación pueda ser interpretada como un reconocimiento de autoría, que, por supuesto, no significa reconocimiento de

\footnotetext{
${ }^{44}$ SÁEZ RODRÍGUEZ (coordinadora): "La mediación familiar. La mediación penal y penitenciaria. El estatuto del mediador. Un programa para su regulación". Ed. Centro de Estudios Jurídicos, Thomson/Aranzadi, 2008, pág. 327.

${ }^{45}$ DEL MORAL GARCÍA, A. en SÁEZ RODRÍGUEZ (coordinadora): "La mediación familiar. La mediación penal y penitenciaria. El estatuto del mediador. Un programa para su regulación". Ed. Centro de Estudios Jurídicos, Thomson/Aranzadi, 2008, pág. 382.
} 
responsabilidad penal, pues no prejuzga la concurrencia de causas de justificación o de exculpación. Por esta razón, la existencia de un reconocimiento de hechos, más o menos claro, es perfectamente compatible con ciertas protestas de inocencia (refiriéndose a eventuales eximentes).

La aparición de ciertas pruebas o la realización de determinados actos que pudieran suponer un mero indicio de culpabilidad no vulnera la presunción de inocencia y, por tanto, podrá ser valorado por el juez. Ello no significa que estemos ante pruebas de culpabilidad, pero sí ante pruebas o conductas valorables. Que el proceso de mediación no suponga actividad probatoria no significa que los actos externos del proceso de mediación sean totalmente neutros desde el punto de vista probatorio.

Obviamente, acceder a iniciar el proceso de mediación es una conducta procesal externa y objetiva que no significa que se admita la culpabilidad, pero que tampoco es neutra desde la perspectiva de la valoración global de la prueba, no resultando razonable ni real obligar a jueces y fiscales, ante el fracaso de la mediación, a actuar como si ésta no se hubiese producido. Sentido común y presunción de inocencia son totalmente compatibles, lo que no sería lógico es negar valor probatorio a la confesión inicial o a las declaraciones de testigos que inculpan en fase de instrucción a una persona porque supongan menoscabar la presunción de inocencia y generan en el juez la impresión de que probablemente el imputado es el autor de los hechos que él mismo reconoce y que le achacan las víctimas. Así, el derecho a la presunción de inocencia exige que sólo tras la celebración de juicio oral y la convicción plena del Tribunal de la autoría de los hechos, basada en la concurrencia de esas pruebas, que quedará plasmada en la correspondiente sentencia firme, se pueda tener a todos los efectos legales por culpable a una persona.

Para que la decisión del imputado de someterse a mediación no le genere dudas por el hecho de que conllevaría una asunción de la autoría de los hechos y su consiguiente condena pese a que desistiese de la continuación del proceso de mediación, sería conveniente que la ley reguladora de la mediación determinase la imposibilidad de valoración $^{46}$. Por ello, habría que informar al imputado para que pudiera adoptar su decisión consciente de estas posibles repercusiones.

\footnotetext{
${ }^{46}$ RÍOS MARTÍN Y OTROS: “La mediación penal y penitenciaria. Experiencias de diálogo y reducción de la violencia y el sufrimiento humano”. Ed. Colex, 2ª ed. 2008, pág. 103.
} 
Se han de tener en cuenta ciertas premisas, no carentes de fundamento, a la hora de valorar lo relativo al procedimiento de mediación, así:

a. Todo lo conocido por el mediador durante dicho proceso es objeto de secreto profesional, $\mathrm{y}$, por tanto, no puede ser obligado a declarar sobre ello (art. 24 de la CE).

b. Igualmente toda la documentación aportada ha de permanecer ajena al proceso judicial, con excepción, en su caso, del acta final. No es una fase destinada a recabar pruebas o a investigar. Las actividades de mediación no son actividades probatorias.

c. La víctima debe respetar el deber de secreto o sigilo sobre las vicisitudes del proceso de mediación de las que haya sido testigo o protagonista en función de la confidencialidad pactada. Debe imponerse a las partes del proceso (acusación pública o particular o popular) la imposibilidad de preguntar sobre tales vicisitudes, aunque, desgraciadamente, se agrave todavía más la victimización. En todo caso, de producirse las declaraciones podrán ser valoradas por el juzgador si se incorporan válidamente al proceso, cumpliendo las exigencias legales establecidas sobre la validez de la prueba.

d. La apertura voluntaria y cierre del proceso de mediación son elementos que pueden ser tomados en consideración dentro de la valoración probatoria. ${ }^{47}$

Lógicamente si la mediación se produce y las partes ratifican el acuerdo, en principio, no existiría problema alguno salvo que, en el acuerdo firmado, el infractor reconociera expresamente los hechos o si se reconocieran en el informe que el mediador presenta al órgano judicial cuando iniciada la mediación se desiste de ella o incluso producido el acuerdo no se ratifica posteriormente. En ambos casos existen opiniones contradictorias, decantándonos por intentar salvaguardar a toda costa el principio de presunción de inocencia para mantener intactas las garantías procesales que confiere la legislación al imputado por un delito, esto es, en ninguno de los supuestos se ha de

\footnotetext{
${ }^{47}$ DEL MORAL GARCÍA, A. en CARABANTE MUNTADA (coordinador): "La mediación: Presente, pasado y futuro de una institución jurídica”. Centro Universitario Villanueva, Madrid. Netbiblo, 2010, pág. 64.
} 
incluir un reconocimiento expreso de hechos dado que esto no impide la efectiva realización, en cualquier caso, del acuerdo y, en todo caso, si preserva este principio de presunción de inocencia de cualquier inferencia.

Lo que se espera de un procedimiento de mediación es que se garantice la confidencialidad, especialmente por el mediador que interviene, y que se produzca la reparación acordada. En caso de acuerdo, se ha de determinar únicamente en qué ha consistido y si se ha realizado, esto lo diferencia del proceso penal. De no existir acuerdo no debe trascender nada (especialmente hacia el juzgador), ya que el supuesto reconocimiento de hechos que pudiera desprenderse por la simple participación no contempla la concurrencia de posibles causas de exención de la responsabilidad, así pues, lo que de mínima actividad probatoria pudiera tener debería servir para beneficiar penalmente al imputado y no para acusarle por hechos no controvertidos, reconocidos y probados en sede judicial.

Es por ello que se ha de relativizar la trascendencia práctica de este problema, adoptando actitudes de cautela y prudencia, pues normalmente se derivarán a mediación supuestos en los que, además de la posibilidad de reparación, o bien se reconocen los hechos (supuesto que habría que dejar a elección del infractor) o bien desde el principio aparece suficiente material probatorio de la autoría. 